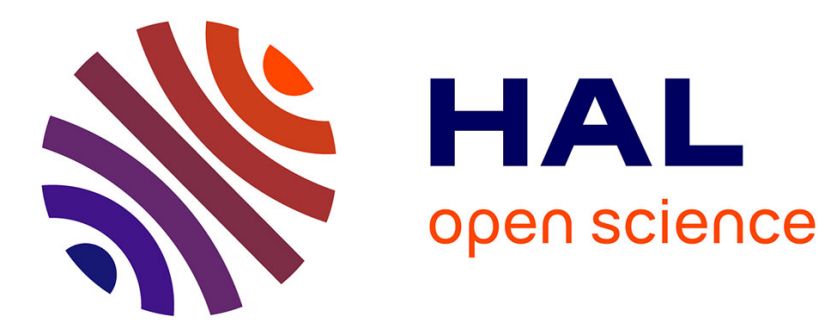

\title{
Superplastic behaviour and mechanical properties of two phase TiAl alloys
}

T. Tsuzuku, H. Sato

\section{To cite this version:}

T. Tsuzuku, H. Sato. Superplastic behaviour and mechanical properties of two phase TiAl alloys. Journal de Physique IV Proceedings, 1993, 03 (C7), pp.C7-389-C7-395. 10.1051/jp4:1993761 . jpa00252180

\section{HAL Id: jpa-00252180 https://hal.science/jpa-00252180}

Submitted on 1 Jan 1993

HAL is a multi-disciplinary open access archive for the deposit and dissemination of scientific research documents, whether they are published or not. The documents may come from teaching and research institutions in France or abroad, or from public or private research centers.
L'archive ouverte pluridisciplinaire HAL, est destinée au dépôt et à la diffusion de documents scientifiques de niveau recherche, publiés ou non, émanant des établissements d'enseignement et de recherche français ou étrangers, des laboratoires publics ou privés. 


\title{
Superplastic behaviour and mechanical properties of two phase TiAl alloys
}

\author{
T. TSUZUKU and H. SATO
}

Mitsubishi Heavy Industries Ltd., Nagoya Aerospace Systems Works, 10 Oye-Cho, Minato-ku, Nagoya 455, Japan

\begin{abstract}
High temperature plastic flow properties of two phase $\mathrm{TiAl}$ alloys containing 45 to 49 at. $\% \mathrm{Al}$ have been investigated in thermo-mechanically grain refined materials in order to clarify the favourable microstructure and chemical composition for TiAl based superplastic materials. Grain sizes of thermomechanical treated materials and their grain size stability during subsequent high temperature deformation strongly depend on chemical composition. It was found that Ti-46at $\% \mathrm{Al}$ offers the best $\alpha_{2} / \gamma$ ratio which produces a fine and stable microstructure, whilst exhibiting superior superplasticity at temperatures exceedig $1100^{\circ} \mathrm{C}$ and a strain rate of around $1 \times 10^{-4} \mathrm{~s}^{-1}$ (with m-value of 0.44 at $1100^{\circ} \mathrm{C}$ and 0.64 at $1150^{\circ} \mathrm{C}$ ) as well as preferred mechanical properties at temperature of up to $1000^{\circ} \mathrm{C}$. This alloy was proposed as a baseline alloy for superplastic materials to be later modified by third elements effective for the formation of metallic phase. Correspondingly, effects of heat treatment on changes in microstructure and tensile properties have been studied in fine grain TiAl alloys in order to estimate the possibility of improving high temperature strength after superplastic forming. A new kind of microstructure consisting of coarse lamellar colonies and fine colony boundary grains of $\gamma$ and lamellar (to be refereed to as partially-transformed structure) was found to be obtained by heat-treatment of just above the $\alpha$-transus. It was also found that the partially-transformed structures exhibit a better combination of room temperature ductility and high temperature strength than any other microstructure previously observed.
\end{abstract}

\section{INTRODUCTION}

Titanium aluminide alloys based on gamma TiAl have recently received considerable attention because of their potential to replace titanium alloys and nickel-base alloys in aerospace systems, such as advanced turbine engines and hypersonic vehicles, where specific strength and stiffness at high temperature are critical. Many attempts focusing on improving mechanical properties of TiAl alloys have been made and significant improvements on room temperature ductility and fracture toughness have been achieved in two phase TiAl alloys during the last couple of years [1]. In addition to improvements of mechanical properties, it is extremely important to improve plastic formability of these materials to put them into practical use. In particular, rendering superplasticity seems to be indispensable to sheet metal forming application of TiAl alloys, which is the most useful methods of fabricating various kinds of lightweight structures.

The possibility of rendering superplasticity to TiAl alloys has been ascertained in several development efforts and N.Mashashi et.al, have shown that formation of $\beta$ phase at grain boundary is very effective to improve superplasticity of $\mathrm{TiAl}$ alloys $[2,3]$. Superplastic materials generally require a fine and stable grain structure. However, methodical knowledge concerning the possible relationship between chemical composition ( $\mathrm{Ti} / \mathrm{Al}$ ratio) / microstructure (grain size and stability) / plastic flow properties has not yet been established sufficiently to optimise the chemical composition and the manufacturing process of superplastic materials. In this work, the influences of $\mathrm{Ti} / \mathrm{Al}$ ratio on microstructure and deformation property were closely studied in order to make clear a binary baseline alloy in which a fine and stable microstructure may be achieved. 
However, superplastic TiAl alloys might exhibit the undesirable properties of high temperature strength and creep resistance because of their fine grain structure. Therefore, superplastic formed parts should require heat-treatment to improve the mechanical properties especially high temperature strength for structural application in hot sections. In this study the effect of heat-treatment on microstructures and mechanical properties of fine grain TiAl alloys were investigated in order to ascertain the possibility of improving the high temperature strength of superplastic formed parts.

\section{EXPERIMENTAL PROCEDURE}

Two phase binary TiAl alloys having five different chemical composition were prepared in Kobe Steel Ltd. using vacuum induction skull melting, homogenisation and thermo-mechanical treatments. Thermo-mechanical treatment was carried out by extrusion with a reduction of cross section area by a factor of four at $1200^{\circ} \mathrm{C}$, followed by annealing. The annealing conditions were optimised respectively for each material within the range of $1000^{\circ} \mathrm{C}$ to $1200^{\circ} \mathrm{C}$ and $5 \mathrm{H}$ to $10 \mathrm{H}$ in order to achieve the finest equiaxed grain microstructure. Aluminium content of thermo-mechanical treated alloys are shown in Table 1. Aluminium content of these materials decreased slightly during thermo-mechanical treatment. Impurity elements are controlled to very low concentrations; the content of oxygen was less than 500ppm, nitrogen and carbon less than 100ppm.

The compression test specimens with dimensions of $12 \mathrm{~mm}$ in both diameter and length as well as tension test specimens having a gage dimensions of $4 \mathrm{~mm}$ in diameter and $6 \mathrm{~mm}$ in length were machined from thermo-mechanical treated materials, making length direction parallel to the axis of extrusion. Deformation properties of these materials were measured over the ranges covering temperatures of $1000^{\circ} \mathrm{C}$ to $1150^{\circ} \mathrm{C}$ and strain rate of $4 \times 10^{-5} \mathrm{~s}^{-1}$ to $5 \times 10^{-3} \mathrm{~s}^{-1}$ by constant strain rate compression and tension tests within a vacuum. Metallographic observation with optical microscopy was made at various stages of deformation.

Heat-treatment tests of these materials were performed at various temperatures between $1100^{\circ} \mathrm{C}$ and $1425^{\circ} \mathrm{C}$ for two hours under vacuum conditions, followed by furnace-cool under a flowing argon atmosphere. Systematic metallographic observation was conducted on heat-treated materials. Cylindrical-gauge tensile specimen having gauge dimensions of $4 \mathrm{~mm}$ in diameter and $15 \mathrm{~mm}$ in length were machined from both heat-treated and non heat-treated materials having typical microstructures. Tensile tests were carried out at room temperature, $800^{\circ} \mathrm{C}$ and $1000^{\circ} \mathrm{C}$ in an argon atmosphere.

Table $1 \mathrm{Al}$ content of TiAl alloys used in this study (at.\%Al).

$\begin{array}{lcc} & \text { as cast } & \text { after TMT } \\ \text { Ti-45at.\%Al } & 45.4 & 44.9 \\ \text { Ti-46at.\%Al } & 46.1 & 45.4 \\ \text { Ti-47at.\%Al } & 47.3 & 46.8 \\ \text { Ti-48at.\%Al } & 47.9 & 47.4 \\ \text { Ti-49at.\%Al } & 49.0 & 48.4\end{array}$

\section{RESULTS AND DISCUSSION}

\section{Effects of Ti/Al Ratio on Microstructure}

\section{(1) Grain Refinement}

Fig. 1 shows typical microstructures of TiAl in as cast and thermo-mechanical treated conditions. The microstructures in as cast condition are coarse lamellar colony structures consisting of alternate $\gamma$ and $\alpha_{2}$ layers, although small amounts of $\gamma$ grains can be observed in Ti-47Al, Ti-48Al and Ti-49Al alloys. After thermo-mechanical treatment, the microstructures becomes a mixture of two kinds of structures, one being a dual-phase equiaxed structure ( $\gamma$ grain $+\alpha_{2}$ grain) having a very fine grain size of about $6 \mu \mathrm{m}$ in diameter, and the other a rather coarse equiaxed $\gamma$ grain structure of $20 \sim 50 \mu \mathrm{m}$ in diameter. Fig. 2 shows the area ratio of a fine dual-phase equiaxed structure as a function of $\mathrm{Al}$ content. The area ratio strongly depends on chemical composition and changes drastically around an $\mathrm{Al}$ content of $47 \mathrm{at} . \%$. This results in 
$\mathrm{Ti}-45 \mathrm{Al}$ and $\mathrm{Ti}-46 \mathrm{Al}$ consisting dominantly of fine dual-phase equiaxed structure, whilst $\mathrm{Ti}-48 \mathrm{Al}$ and $\mathrm{Ti}-$ 49Al consist mainly of equiaxed $\gamma$ grain structure.

The area ratio of a fine dual-phase equiaxed structure may depend in principle on the ratio of $\gamma$ phase and $\alpha_{2}$ phase contained in these materials. However, considering that equiaxed $\gamma$ grains should nucleate during annealing at the colony and grain boundaries of lamellar and $\gamma$ grains, the area ratio may more or less be controlled by optimising as cast microstructure and subsequent thermo-mechanical processes. Although fine grain structures could be achievable in Ti-46Al and Ti-45Al to the same extent, Ti-45Al is much more difficult to break up its lamellar structure entirely through thermo-mechanical treatment due to its larger $\alpha_{2}$ phase content. Therefore it should be concluded that Ti-46Al offers the best $\alpha_{2} / \gamma$ ratio in obtaining a fine grain structure and is therefore most desirable as a superplastic material.

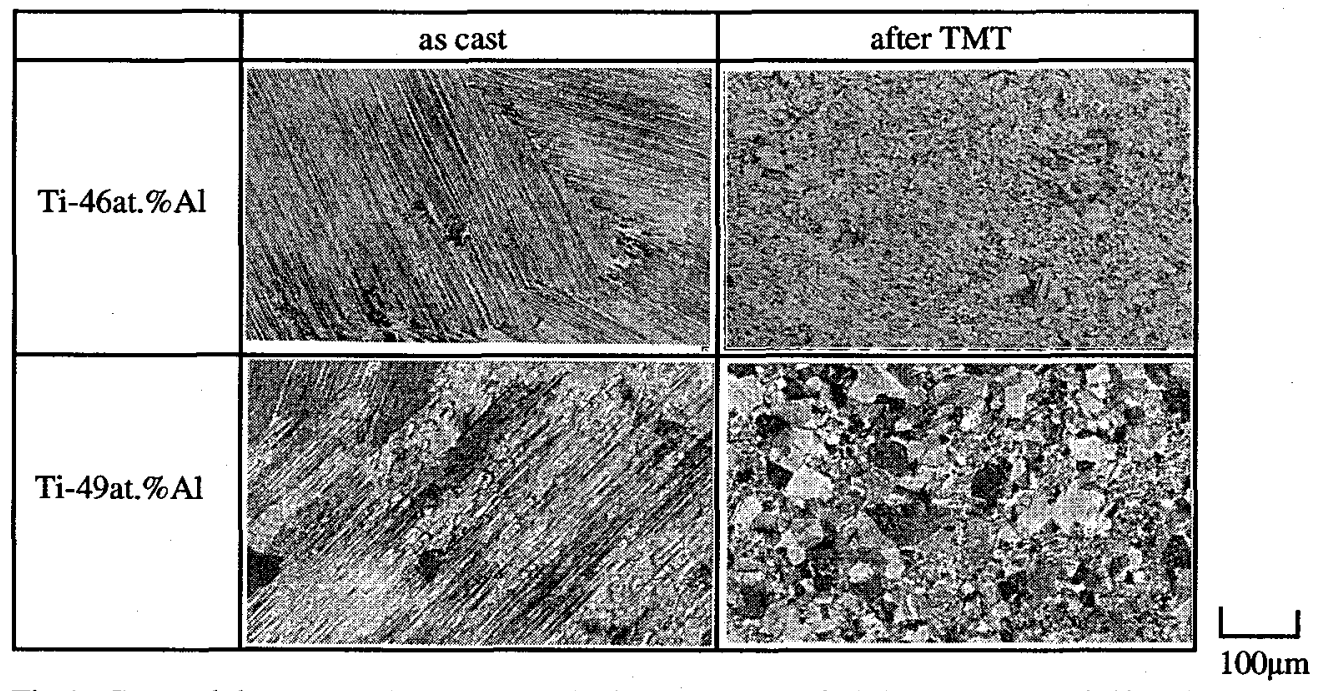

Fig.1 Cast and thermo-mechanical treated microstructures of Ti-46at.\% Al and Ti-49at.\%Al.

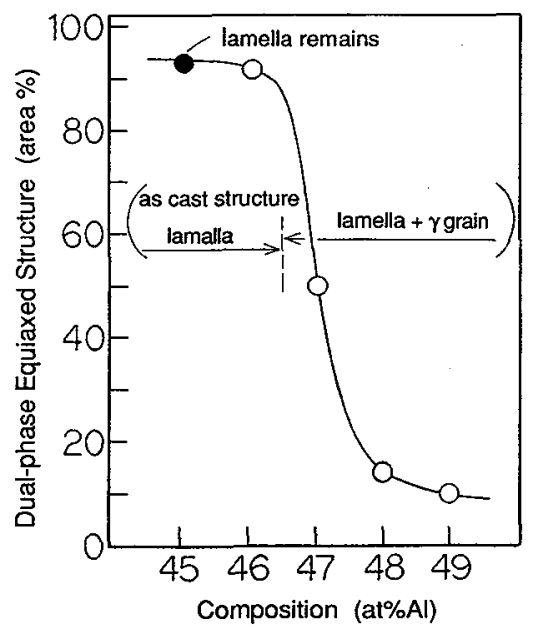

Fig.2 The area ratio of a fine dual-phase equiaxed structure as a function of aluminium content.

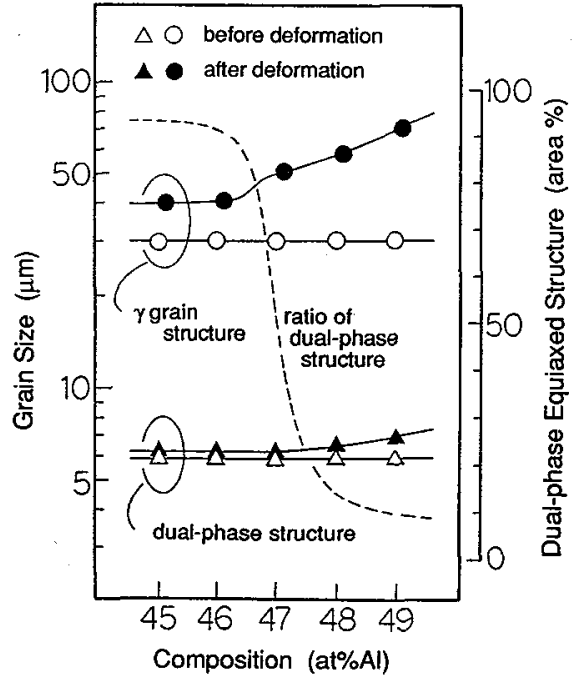

Fig.3 Changes in the mean grain sizes during compressive deformation of $50 \%$ reduction at the condition of $1100^{\circ} \mathrm{C}$ and $2 \times 10^{-4} \mathrm{~s}^{-1}$. 
(2) Microstructural Stability

Fig. 3 shows changes in grain size during compressive deformation of $50 \%$ reduction performed at the condition of $1100^{\circ} \mathrm{C}$ and $2 \times 10^{-4} \mathrm{~s}^{-1}$. Grain size stability during high temperature deformation are quite different between dual-phase equiaxed structure and equiaxed $\gamma$ grain structure. During this deformation the former remains as fine as the initial, whilst the latter exhibits considerable grain coarsening.

Previous work in Ti-48Al-1Mn, in which equiaxed $\gamma$ grain structure is dominant, has apparently shown that the grain coarsening of equiaxed $\gamma$ grain structures is caused by dynamic recrystallization. Fig. 4 shows the grain size after compressive deformation measured in Ti-48Al-1Mn having initially three different grain sizes. Grain sizes after deformation depend only on the deformation condition represented by Zener-Hollomon parameter $(\mathrm{Z}=\dot{\varepsilon} \cdot \exp (\mathrm{Q} / \mathrm{RT}))$ and are therefore independent of initial grain sizes. In general, a better superplasticity should be achievable at deformation conditions corresponding to a smaller $Z$ parameter. However, TiAl alloys consisting of equiaxed $\gamma$ grain structure exhibit considerable grain coarsening with a reduction in $Z$, which results in unsatisfactory superplasticity. In this respect, a dualphase equiaxed structure is indispensable to superplastic materials, as well as Ti-46Al, in which a fine dual-phase equiaxed structure is dominant, seems to be most suitable for superplastic forming.

\section{Plastic Flow Properties of TiAl alloys}

Based on the plastic flow properties of these alloys measured by compression tests, compositional dependence of $\mathrm{m}$-value and flow stress at the strain rate of $1 \times 10^{-4} \mathrm{~s}^{-1}$ are summarised in Fig.5. At the temperature conditions of up to $1050^{\circ} \mathrm{C}$, strain rate sensitivity indices "m" remain below 0.3 and superplastic flow was not observed in any material. Flow stresses of these materials simply decrease with increasing $\mathrm{Al}$ content. At the temperature condition of $1100^{\circ} \mathrm{C}$, Ti-46Al exhibits superior superplasticity to the others. When the maximum m-value reaches 0.44 , the flow stress decreases significantly. The reason why $\mathrm{Ti}-46 \mathrm{Al}$ displays exceptional plastic flow properties must be because this material has a higher volume fraction of fine and stable dual-phase microstructure than the others and is free from residual lamellar structure. A drastic change in deformation properties of Ti-46Al between $1100^{\circ} \mathrm{C}$ and $1050^{\circ} \mathrm{C}$ implies change in the deformation mechanism which suggests that a grain boundary sliding should play a major role in deformation of this alloy at $1100^{\circ} \mathrm{C}$.

Plastic deformation properties of $\mathrm{Ti}-46 \mathrm{Al}$ and $\mathrm{Ti}-47 \mathrm{Al}$ measured by tension tests are shown in Fig.6. Plastic deformation property at $1100^{\circ} \mathrm{C}$ is almost the same as that measured by compression tests. Ti-46Al also indicates a good superplasticity under a tensile stress condition.

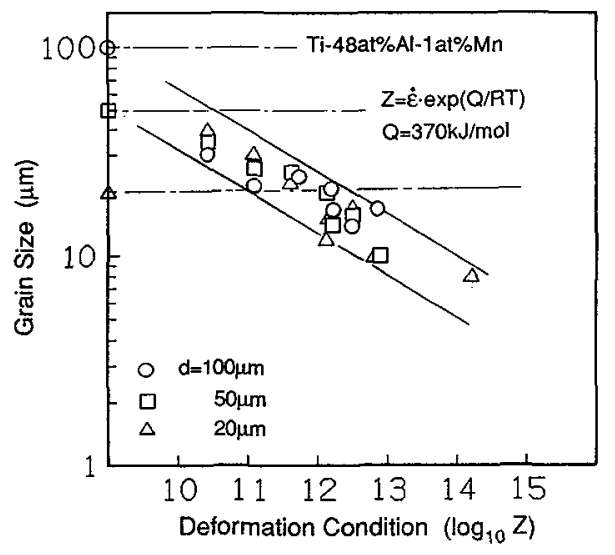

Fig.4 Grain size after $50 \%$ compressive deformation of Ti-48Al-1Mn as a function of deformation condition, $\mathrm{Z}=\dot{\varepsilon} \cdot \exp (\mathrm{Q} / \mathrm{RT})$.

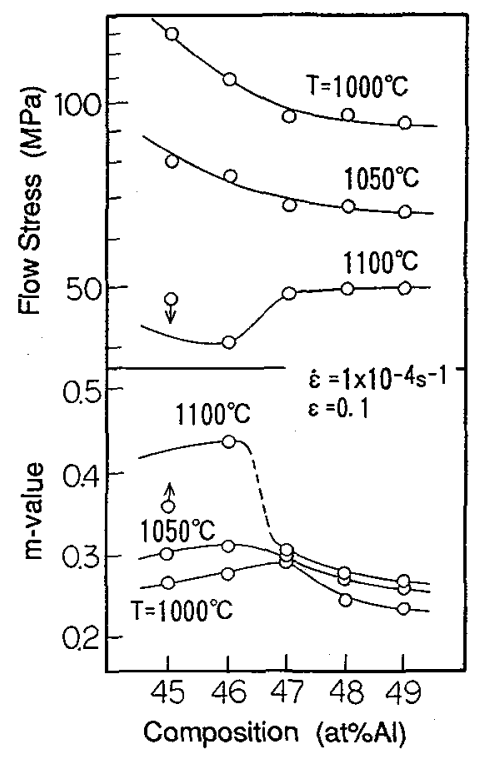

Fig.5 Dependence of flow stress and m-value on chemical composition at temperature range of $1000^{\circ} \mathrm{C}$ to $1100^{\circ} \mathrm{C}$ at strain rate of $1 \times 10^{-4} \mathrm{~s}^{-1}$. 
In particular, it is noticeable that an m-value of over 0.6 was obtained at the condition of $1150^{\circ} \mathrm{C}$ and $1 \times 10^{-4} \mathrm{~s}^{-1}$. As $\alpha_{2}$ phase should be transformed into metallic $\alpha$ phase at $1150^{\circ} \mathrm{C}$, this improvement of superplasticity seems to be due to the formation of metallic $\alpha$ phase. Ti-46Al exhibited a superplastic elongation over $280 \%$, which is the limit measurable for the equipment, without conspicuous local necking at a strain rate of $1 \times 10^{-4} \mathrm{~s}^{-1}$ at $1100^{\circ} \mathrm{C}$ and $1150^{\circ} \mathrm{C}$.

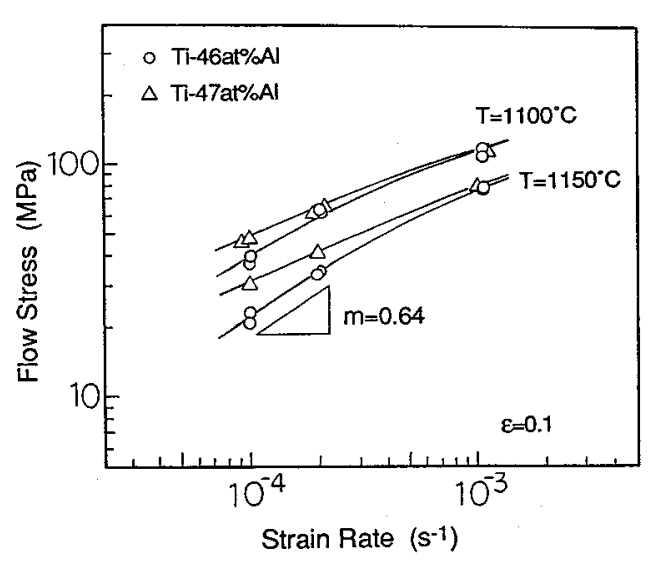

Fig.6 Plastic flow properties of Ti-46at.\%Al and $\mathrm{Ti}-47 \mathrm{at} . \% \mathrm{Al}$ measured by constant strain rate tension tests.

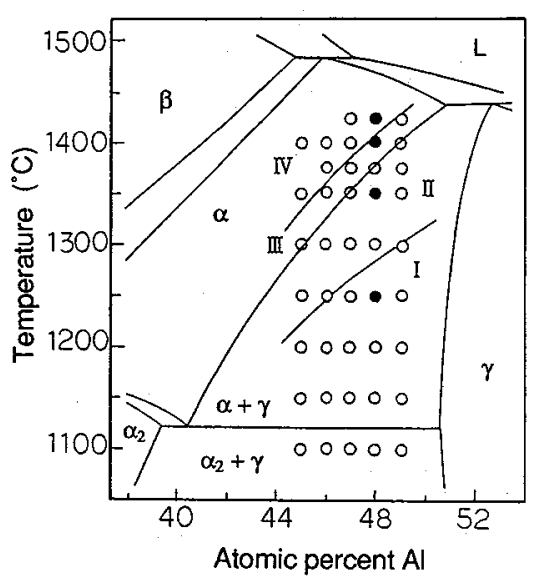

Fig.7 Four heat-treatment temperature regions corresponding to different kinds of microstructure shown in Fig.8.

\section{Microstructural Change by Heat-Treatment}

Systematic metallographic examination of heat-treated materials showed that the microstructures were classified into four categories, although each microstructure varies in grain size and volume fractions of constituent phases depending on chemical compositions. Fig.7 and Fig.8 show these variations of heat-treatment temperature regions and their respective microstructures. The first structure is a dual-phase equiaxed structure obtained by heat-treatment in the lower temperature region of the two phase $(\alpha+\gamma)$ field. This structure is the same as the initial, except a considerable grain coarsening has occurred. The second one is a duplex structure obtained by heat-treatment in the higher temperature region of the two phase field. This structure consists of $\gamma$ grains and lamellar grains, which are a transformed form of the high temperature $\alpha$ phase. The third variation is a very peculiar structure consisting of coarse lamellar colonies and fine colony boundary grains of $\gamma$ and lamellar, which can be obtained by heat-treatment in the narrow temperature range of just above the $\alpha$-transus. This structure has not been previously observed, it will in future be referred to as partially-transformed structure. The forth microstructure is a fully-transformed structure obtained by heat-treatment in single phase $(\alpha)$ field.

K.S.Chan and Y.W.Kim have observed a microstructure somewhat similar to the partiallytransformed structure, i.e. small amounts of equiaxed $\gamma$ grains at colony boundaries have been observed [4]. However, the partially-transformed structure contains much larger amounts of colony boundary grains than the previously observed structure and proved to have distinctive mechanical properties.

\section{Microstructural Dependence of Tensile Properties}

Fig. 9 shows the tensile properties of non heat-treated materials at room temperature, $800^{\circ} \mathrm{C}$ and $1000^{\circ} \mathrm{C}$. Tensile strength and room temperature ductility increases with decreasing $\mathrm{Al}$ content. This results conflicts with some previous reports, which show that room temperature elongation decreases when the content of $\alpha_{2}$ phase becomes higher than that of Ti-48Al [5,6]. Also creep resistance decreases with increasing $\alpha_{2}$ phase content [7]. Unlike previous work, this study incorporates material having a very fine grain structure, especially $\mathrm{Ti}-45 \mathrm{Al}$ and $\mathrm{Ti}-46 \mathrm{Al}$. Accordingly, large elongation achieved in 


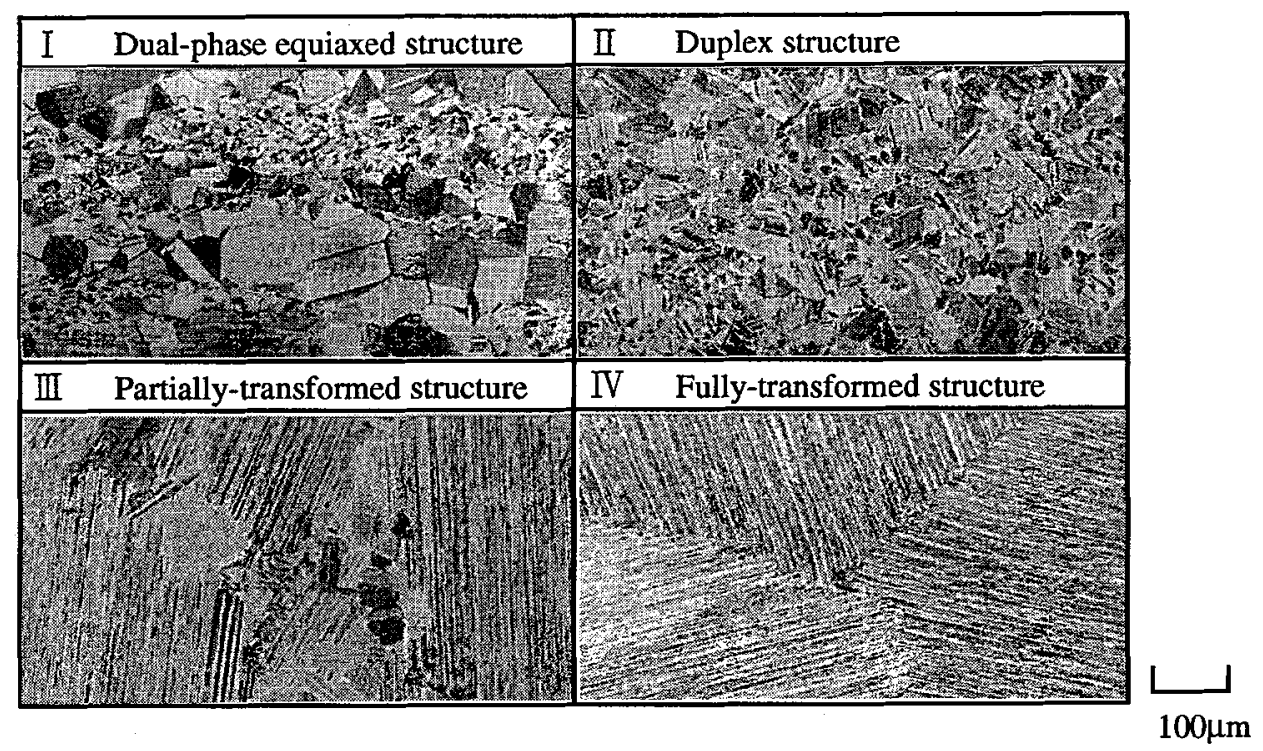

Fig.8 Four kinds of typical microstructure obtained by heat-treatment in Ti-48at.\%Al.

Al-lean alloys may imply that the grain size should have greater effect on room temperature ductility than the $\alpha_{2}$ phase content. In respect of high temperature strength, fine grain structure of Al-lean alloys can be considered undesirable. However, both high temperature strength in Fig.9 and flow stress in Fig.5 increase with decreasing Al content, which apparently indicates that the increase in the $\alpha_{2}$ phase content should be responsible for the increase in high temperature strength. The same dependence of tensile properties on chemical composition was observed in every microstructure obtained by heat-treatment. Therefore, it can be concluded that $\mathrm{Ti}-46 \mathrm{Al}$ combines superior superplasticity at temperatures of above $1100^{\circ} \mathrm{C}$ with preferred tensile properties at temperatures of up to $1000^{\circ} \mathrm{C}$.

Fig.10 shows the effect of microstructural change by heat-treatment on tensile properties at room

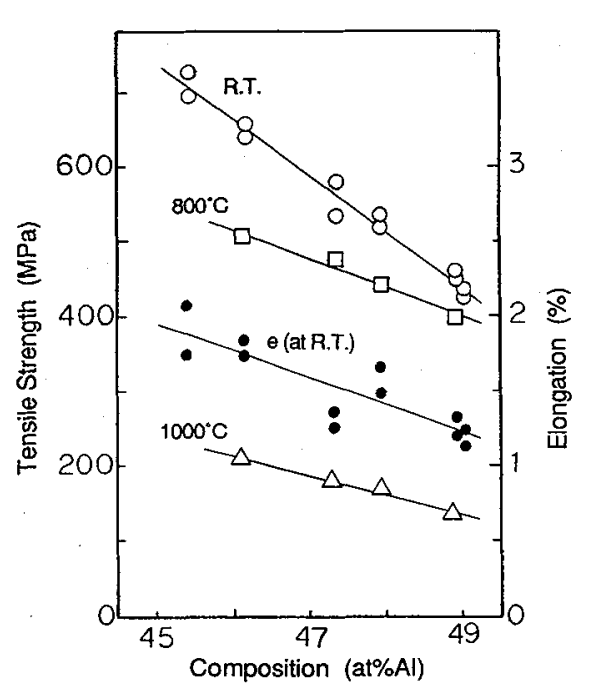

Fig.9 Tensile properties of thermomechanical treated (non heat-treated) materials as a function of $\mathrm{Al}$ content.

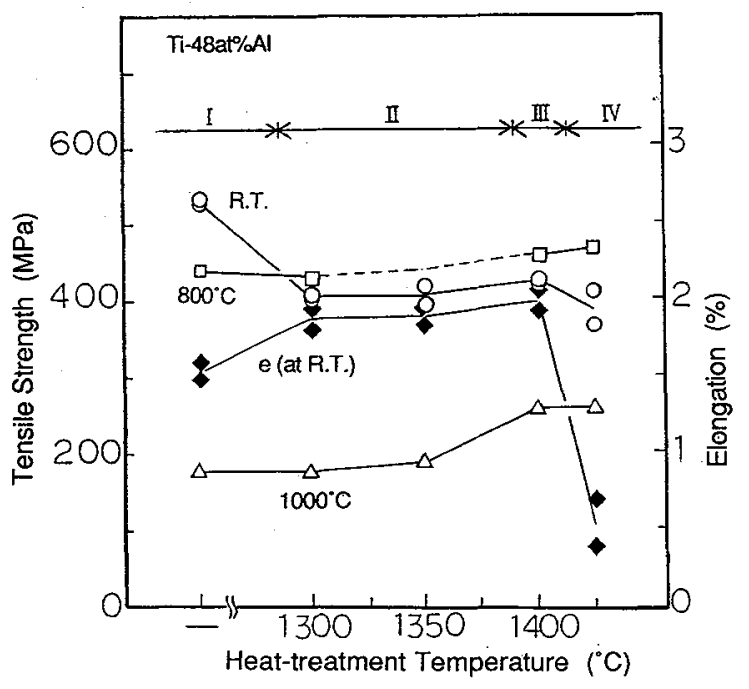

Fig.10 Effect of microstructural change due to heat-treatment on tensile properties at room temperature, $800^{\circ} \mathrm{C}$ and $1000^{\circ} \mathrm{C}$. 
temperature, $800^{\circ} \mathrm{C}$ and $1000^{\circ} \mathrm{C}$. The decrease in room temperature strength apparently observed after heat-treatment seems to be caused by fully recrystallization during heat-treatment. This suggests that considerable amounts of dislocation substructure should be retained after thermo-mechanical treatment. Therefore tensile strength should decrease to the same extent after superplastic forming. Duplex structure is characterised by better room temperature ductility and fully-transformed structure by better high temperature strength, which is consistent with previous observations done by D.S.Shih et al. [8]. It is also found in this figure that duplex structure has not shown much indication that high temperature strength could be improved. This implies that lamellar structure should be essential to improving it meaningfully, whilst fully-transformed structure has exhibited negligible room temperature ductility. Partially-transformed structure, however, has surprisingly exhibited a good combination of room temperature ductility and high temperature strength. Its room temperature ductility is no less than that of duplex structure and at the same time its high temperature strength is as high as that of fully-transformed structure. Although optimising the heat-treatment conditions to obtain appropriate partially-transformed structure and making clear the mechanism which creates room temperature ductility in this structure still remain as the subject of major investigation, the possibility of improving high temperature strength without sacrificing room temperature ductility is ascertained.

\section{CONCLUSIONS}

(1) Ti-46Al offers the optimum $\alpha_{2} / \gamma$ ratio to make a fine and stable microstructure achievable through thermo-mechanical treatment. Fine grain Ti-46Al displays superior superplasticity to the other alloys at temperatures of above $1100^{\circ} \mathrm{C}$ and a strain rate of around $1 \times 10^{-4} \mathrm{~s}^{-1}$, with $\mathrm{m}$-value of 0.44 at $1100^{\circ} \mathrm{C}$ and 0.64 at $1150^{\circ} \mathrm{C}$. This alloy is most promising as a baseline alloy for superplastic alloys which can be modified by third elements effective for the formation of metallic phase.

(2) Fine grain $\mathrm{Ti}-46 \mathrm{Al}$ exhibits better room temperature ductility and tensile strength at temperature of up to $1000^{\circ} \mathrm{C}$ than the other alloys containing larger amounts of Al. This dependence of tensile properties on $\mathrm{Al}$ content is retained even in various microstructures obtained by subsequent heat-treatment.

(3) A new kind of microstructure refereed to as partially-transformed structure is obtained by heattreatment in the narrow temperature range just above the $\alpha$-transus. This structure consists of coarse lamellar colonies and fine colony boundary grains of $\gamma$ and lamellar. It exhibits a good combination of room temperature ductility and high temperature strength, which has shown the possibility of improving high temperature strength without sacrificing room temperature ductility.

\section{ACKNOWLEDGEMENT}

Most of this work were performed under the management of R\&D Institute of Metals and Composites for Future Industries (RIMCOF) as a part of the R\&D project of basic technologies for future industries supported by New Energy and Industrial Technology Development Organisation (NEDO).

\section{REFERENCES}

1. Y.W.Kim : Intermetallic Compounds - Structure and Mechanical Properties - JIMIS 6, edited by O.Izumi, Japan Institute of Metals, 1991, pp.753

2. S.C.Cheng, J.Wolfenstine and O.D.Sherby : Metall trans. A, 23A (1992), 1509

3. N.Masahashi, Y.Mizuhara, M.Matsuo, T.Hanamura, M.Kimura and K.Hashimoto : ISIJ Int., 31 (1991), 728

4. K.S.Chan and Y.W.Kim : Metall trans. A, 23A (1992), 1663

5. S.C.Huang and E.L.Hall : Metall trans. A, 22A (1991), 427

6. S.C.Huang and E.L.Hall : Metall trans. A, 22A (1991), 2619

7. W.E.Dowling, B.D.Worth, J.E.Allison and J.W.Jones: Microstructure/Property Relationships in Titanium Aluminides and Alloys, edited by Y.W.Kim and R.R.Boyer, TMS, 1991, pp.123

8. D.S.Shih, S.C.Huang, G.K.Scarr, H.Jang and J.C.Chesnutt : Microstructure/Property Relationships in Titanium Aluminides and Alloys, edited by Y.W.Kim and R.R.Boyer, TMS, 1991, pp.135 